\title{
EVALUATION OF THE NON-PERTURBED TEC REFERENCE OF A NEW VERSION OF THE DIX
}

\author{
Giorgio Arlan da Silva Picanço', Clezio Marcos Denardini', Paulo Alexandre Bronzato Nogueira', \\ Paulo França Barbosa Neto, Láysa Cristina Araújo Resende ${ }^{1,3}$, Carolina de Sousa do Carmo', \\ Esmeralda Romero Hernandez ${ }^{4}$, Sony Su Chen ${ }^{1}$, Juliano Moro ${ }^{1,3}$ and Regia Pereira da Silva ${ }^{5}$
}

\begin{abstract}
In the present work, we evaluate a new method for determining a non-perturbed Total Electron Content (TEC) reference to apply on a new version of the disturbance ionosphere index (DIX). This method is based on calculating a 3-hour moving average over the TEC obtained during a given reference day. We compared the proposed method with TEC values obtained from monthly medians and the International Reference lonosphere (IRI) model to evaluate its performance. The results are presented and discussed in terms of a dispersion coefficient between each method and the averaged TEC from the five quietest days of each month of 2015, over three Brazilian sites. Finally, we calculated the DIX based on the proposed method and compared it with the original DIX values obtained during the St. Patrick's Day magnetic storm (17-18 March 2015). Differences between the two approaches are discussed, and the results showed that the non-perturbed reference determination could highly influence the quality of the DIX calculation.
\end{abstract}

Keywords: TEC, DIX, ionospheric indices, space weather.

RESUMO. No presente trabalho, avaliamos um novo método para determinar um Conteúdo Eletrônico Total (TEC) de referência para aplicá-lo em uma nova versão do índice de perturbação da ionosfera (DIX). Este método baseia-se no cálculo de uma média móvel de 3 horas sobre o TEC obtido durante um determinado dia de referência. Comparamos o método proposto com os valores de TEC obtidos a partir de medianas mensais e do modelo IRI para avaliar o seu desempenho. Os resultados são apresentados e discutidos em termos de um coeficiente de dispersão entre cada método e a média do TEC para os cinco dias mais calmos de cada mês de 2015, em três localidades brasileiras. Finalmente, calculamos 0 DIX com base no método proposto e o comparamos com os valores de DIX originais obtidos durante a tempestade geomagnética do dia de St. Patrick (1718 de março de 2015). As diferenças entre as duas abordagens são discutidas, e os resultados mostram que a determinação do TEC de referência não perturbado pode influenciar diretamente a qualidade do índice DIX.

Palavras-chave: TEC, DIX, índices ionosféricos, clima espacial. 


\section{INTRODUCTION}

Ionospheric disturbances have a strong influence on the performance of Global Navigation Satellite Systems (GNSS) (e.g. GPS, GLONASS, and Galileo). These effects may include errors caused by rapid phase and amplitude fluctuations, as well as interruptions in the satellite-receiver connection (Jakowski et al., 2012a). These disturbances can be defined in terms of the ionospheric Total Electron Content (TEC) variations, being mainly related to phenomenon driven by solar events and/or associated with dynamical processes of the atmosphere (Batista et al., 1991; Sobral et al., 1997; Abdu et al., 2006; Takahashi et al., 2016). In this context, many efforts have been made to develop indices to represent the ionospheric response due to these drivers (Jakowski \& Hoque, 2019; Resende et al., 2019). Denardini et al. (2020) present a list of some of the most well-known ionospheric indices and a basic description of their methodologies. These indices have been developed aiming to provide a quick measure of the disturbed ionospheric variations. Also, many examples using TEC-based indices can be found in the literature (Gulyaeva \& Stanislawska, 2008; Sanz et al., 2014; Wilken et al., 2018).

It is primarily necessary to understand what a typical TEC variation is before to define a threshold for a disturbed behavior. With that in mind, we intend to make it clear the difference between an ionospheric background value (TEC reference) and a disturbed value (variation in relation to reference). These two parameters have been widely used to study ionospheric variations with different time scales (Figueiredo et al., 2017, 2018; Takahashi et al., 2018; Shinbori et al., 2018; Tsugawa et al., 2018).

The DIX is an ionospheric index proposed in a first formulation by Jakowski et al. (2006) and later evolved through the modification and inclusion of various parameters (Jakowski et al., 2012a, 2012b; Jakowski \& Hoque, 2019; Wilken et al., 2018; Denardini et al., 2020). The DIX corresponds to a value of the ionospheric degree of perturbation, and it was originally based on the TEC variation over a background calculated from TEC monthly medians, here referred to as a 'non-perturbed reference'. Denardini et al., (2020), in turn, used TEC moving averages over a given reference day to calculate the reference for the DIX. Therefore, the main aim of this study is to evaluate the method proposed by Denardini et al. (2020) to obtain a non-perturbed reference for the new DIX equation presented in the same study (here referred to as "new DIX"). Therefore, we demonstrate that the proposed method leads to an acceptable reference for the new DIX by comparing it with some other techniques, such as the original one used by Jakowski et al. (2006), and another one defined by the use of TEC data obtained from the IRI model (Bilitza et al., 2017). Those comparisons were performed in terms of their similarities with the averaged TEC obtained from the five geomagnetically quietest days of each month of 2015, determined by the German Research Centre for Geosciences (GFZ). Finally, we calculated the new DIX values by using the proposed non-perturbed reference over the period around the St. Patrick's Day magnetic storm (17-18 March 2015) and compared it with the DIX values obtained from the original methodology towards discussing the differences between both techniques. The results showed that the method proposed by Denardini et al. (2020) is valid as an adequate alternative to represent the non-perturbed reference for the new DIX.

\section{METHODOLOGY}

\section{Original DIX and new DIX calculation}

The DIX for such an observation point (here referred to as original DIX) can be calculated from the following equation (Jakowski et al., 2006; Denardini et al., 2020):

$$
D I X_{k}(t)=\sqrt{\left[\frac{T E C_{k}(t)-T E C_{k}^{a v g}(t)}{T E C_{k}^{a v g}(t)}\right]^{2}}
$$

where $T E C_{k}(t)$ is the vertical TEC value obtained for a given time and observation point, $k=$ (latitude, longitude), and $T E C_{k}^{a v g}(t)$ is the corresponding TEC monthly median.

Denardini et al. (2020), after made some modifications, presented their version of the DIX (here referred to as new DIX), considering some new terms. The new DIX is defined by the Equation (2):

$$
\operatorname{DIX}_{k}(t)=\sqrt{\left(\frac{\alpha\left(\Delta T E C_{k}(t) / T E C_{k}^{Q d}(t)\right)+\Delta T E C_{k}(t)}{\beta}\right)^{2}}
$$

where $T E C_{k}(t)$ is the same term described in Equation (1), $T E C_{k}^{Q d}(t)$ corresponds to the proposed non-perturbed reference value at a given time for the observation point. The 
term $\Delta T E C_{k}(t)=\left|T E C_{k}(t)-T E C_{k}^{Q d}(t)\right|$ and the coefficient $\alpha$ (both given in TEC units) intend to improve the new DIX sensitivity to internal drivers as well as to normalize its response irrespective of the local time. Finally, the coefficient $\beta$ (also given in TEC units) is chosen to normalize the DIX output into a scale ranging from 0 to 5 . More details about the coefficients $\alpha$ and $\beta$ calculation are given in Denardini et al. (2020).

\section{Overview of the new non-perturbed TEC reference}

As proposed by Jakowski et al. (2006), monthly medians are a simple method to represent a non-perturbed TEC reference. However, including data obtained during geomagnetically disturbed periods may lead the reference values to be contaminated with a noise due to perturbation effects occurring in the selected month (e.g. positive/negative ionospheric storms due to prompt penetration electric fields) (Kelley et al., 1979; Blanc \& Richmond, 1980; Abdu et al., 2006; Nogueira et al., 2011; de Siqueira et al., 2011). Thus, we present a study of the method to determine a nonperturbed reference for the new DIX as it was proposed by Denardini et al. (2020). The method is based on the use of a centered moving average of the TEC obtained during a reference day along a period of interest of up to 10 days. This time window is set to mitigate seasonal effects. In this regard, the reference day is defined as the geomagnetically quietest day of the 10-day period where no plasma depletions greater than 20 TEC units (associated with plasma bubble/spread-F) were detected in the daily TEC curve (Denardini et al., 2020). With this in mind, the geomagnetically quietest day is firstly selected from the list provided by GFZ Potsdam, and the presence/absence of spread- $F$ is posteriorly confirmed by observing ionograms from a low-latitude station close by the sector being analyzed. In this sense, the reference day is supposed to represent a quiet pattern considering geomagnetic and ionospheric features.

\section{Non-perturbed TEC reference calculation}

The non-perturbed TEC reference can be obtained by calculating a centered moving average over the TEC data related to the above-mentioned reference day. Therefore, the non-perturbed reference, MAQd, can be obtained using the Equation (3):

$$
\operatorname{MAQd}(\mathrm{t})=\frac{1}{2 w+1} \sum_{\delta=-w}^{w} \operatorname{TEC}(t+\delta)
$$

where $\operatorname{TEC}(t)$ is the TEC value at a given time, $t$, the term $\delta$ is the lower limit of the moving average time scale (given in minutes), and $w$ is the point that should delimit the sampling scale so that the non-perturbed reference value obtained has a time position equivalent to $T E C_{k}$ on the DIX equation.

The $w$ value is given by:

$$
w= \begin{cases}(N-1) / 2, & \text { if } N \text { is odd } \\ (N / 2)-1, & \text { if } N \text { is even }\end{cases}
$$

where $\boldsymbol{N}$ is the number of samples contained in the moving average window (e.g. for 60 minutes, $\boldsymbol{N}=\mathbf{6 0}$ ).

\section{DATA SET AND EVALUATION OF THE METHOD}

To empirically evaluate the efficacy of the new method in representing a non-perturbed reference, we used the TEC values obtained from TEC maps at three ground-based GNSS stations in Brazil: São Luís (SLZ, 2.53ㅇ, $44.30^{\circ} \mathrm{W}$ ), São José dos Campos (SJC, $\left.23.17^{\circ} \mathrm{S}, 45.88^{\circ} \mathrm{W}\right)$, and Santa Maria (SMA, $\left.29.69^{\circ} \mathrm{S}, 53.80^{\circ} \mathrm{W}\right)$.

Figure 1 shows an example of the Embrace/INPE TEC map over South America including the geographical locations of the three GNSS stations used in the present work (SLZ, SJC, and SMA). The solid black line across the map represents the magnetic equator in 2015. 


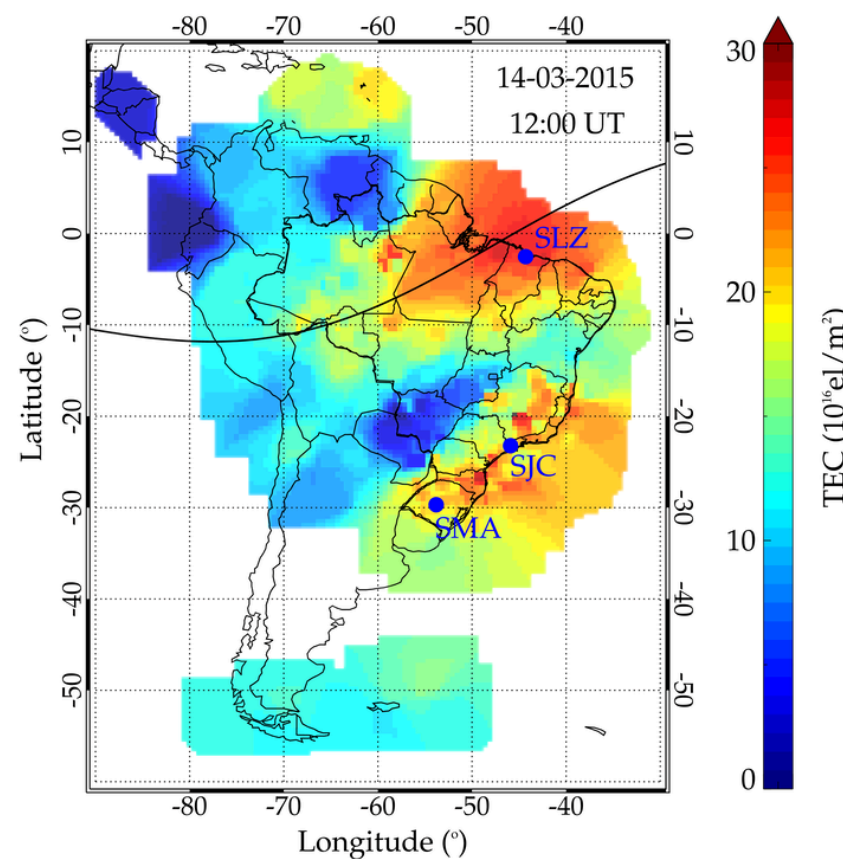

Figure 1 - TEC map on 14 March, 2015 showing the geographic locations of the three GNSS stations used in this study: SLZ, SJC, and SMS.

Considering the Figure 1, we have chosen each of the three locations from the following requirements:

- One site located in the neighborhood of the magnetic equator (SLZ);

- One site located nearby the Equatorial Ionization Anomaly (EIA) southern crest (SJC); and

- One site located south of the southern EIA crest (SMA).

Thus, we calculated the non-perturbed reference values for the year 2015 using the methods described in Denardini et al. (2020). These calculations were made for the three sites within three different time scales: 1 hour (1hMAQd), 3 hours (3hMAQd), and 6 hours (6hMAQd). We compared the non-perturbed series (1-, 3- and 6h-MAQd) with the TEC monthly medians and with the TEC data provided by the IRI model, for the same period and same sites, aiming to evaluate the best methodology for the non-perturbed TEC reference. These comparisons were made from the determination of a similarity parameter between each method and the average of the TEC obtained during the five geomagnetically quietest days of each month (here referred as to "quiet TEC"), as an attempt to correlate each reference TEC values with a geomagnetically quiet reference.
To calculate the above-mentioned similarity parameter, we propose a simple and useful dispersion coefficient, $\chi$, given by the Equation (5):

$$
\chi=\sqrt{(1-a)^{2}+(1-r)^{2}}
$$

where $\boldsymbol{a}$ is the slope of the linear regression between the TEC reference (MAQd, Monthly Medians or TEC-IRI) and the quiet TEC measurements, and the term $\boldsymbol{r}$ is the Pearson's correlation coefficient between the same values.

Therefore, we have a simple parameter whose value corresponds to a single dispersion coefficient. Thus, the closer to zero the $\chi$ value is, the closer the non-perturbed reference TEC values are to the quiet TEC values, attesting to the quality of the method.

\section{RESULTS AND DISCUSSIONS}

\section{Analysis of the coefficients}

Here we intend to compare the non-perturbed reference values obtained from the different methods with the quiet TEC values, which are an average of the TEC obtained during the five geomagnetically quietest days of a given month. Thus, Figure 2 displays the scatter plots of the non-perturbed references calculated from the monthly medians (black symbols), TEC-IRI (red symbols), 1hMAQd (blue symbols), 3hMAQd (orange symbols), and 6hMAQd (green symbols) at (a) SLZ, (b) SJC, and (c) SMA versus the quiet TEC (qTEC) values obtained in March 2015, respectively.

Two features can be easily observed in Figure 2 . The first one is that all non-perturbed values related to qTEC values tend to be more dispersed on the TEC site located in the ElA southern crest (SJC). This characteristic can be explained by the mechanism described in Abdu (2005), who states that due to the increase (decrease) of the eastward zonal electric field, the transport of plasma driven by the fountain effect is also intensified (decreased) causing plasma from the ElA crest to be displaced towards higher (lower) latitudes. Moreover, Abdu (2005) emphasizes the 

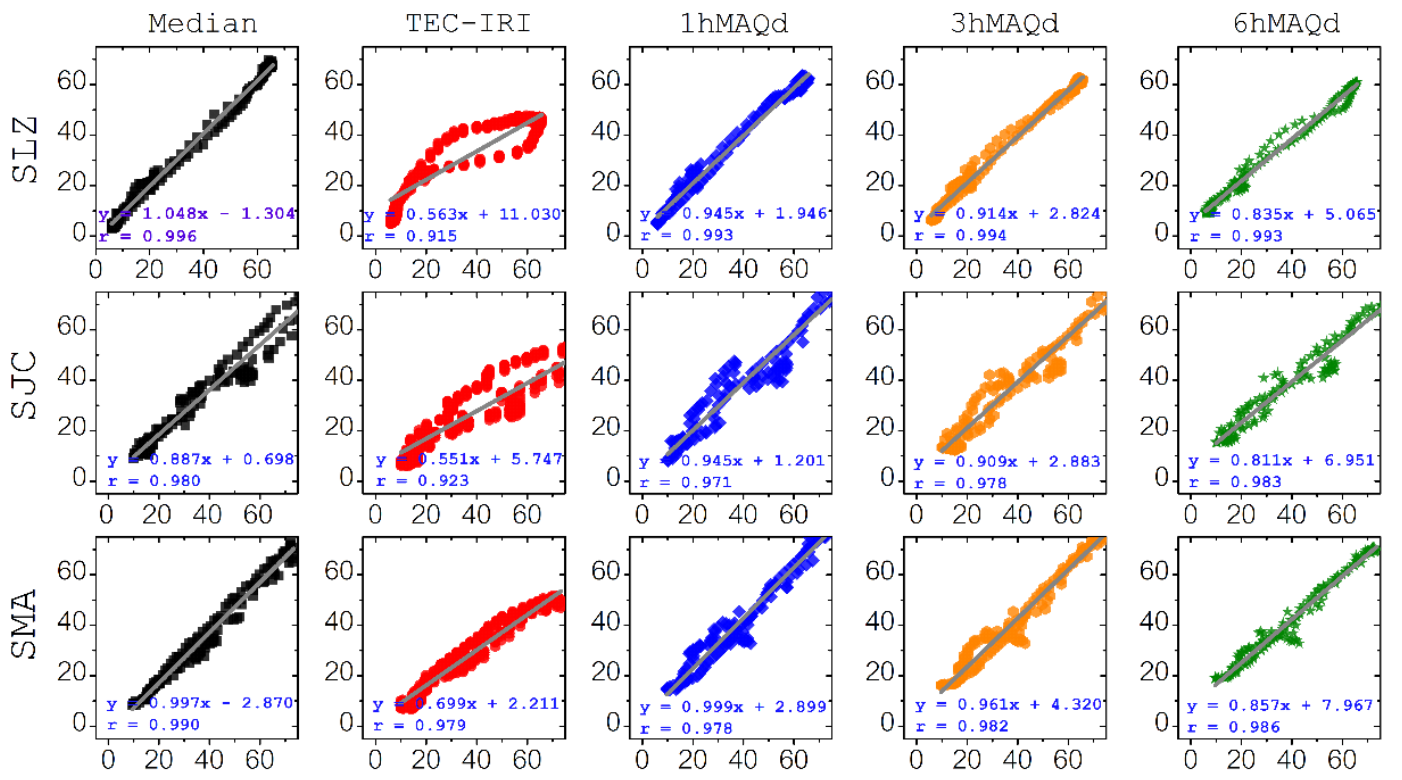

Figure 2 - Scatter plots of the non-perturbed references calculated from the monthly medians (black symbols), TEC-IRI (red symbols), 1hMAQd (blue symbols), 3hMAQd (orange symbols), and 6hMAQd (green symbols) at (a) SLZ, (b) SJC , and (c) SMA against the qTEC values in March 2015, respectively.

importance of the thermospheric meridional wind for the position of the EIA crest. Thus, the EIA crest behavior makes TEC at SJC to be more variable than others with respect to its day-to-day variability. The other feature is that all methods have $\boldsymbol{r}$ Pearson's correlation coefficient values greater than 0.9 . Thus, it is difficult to select a nonperturbed reference method for the new DIX just considering the $\boldsymbol{r}$ value. Therefore, we decided to select it from the results coming from the dispersion coefficient (see Equation 5).

The corresponding annual averages of the dispersion coefficient values for each non-perturbed reference method are listed in Table 1. It is observed that the nonperturbed reference method that comes closest to qTEC is the one obtained from the calculation of a 1-hour moving average over the TEC obtained during the reference day (1hMAQd). The monthly medians and the 3hMAQd methods are quite similar, having even equal $\chi$-values for the SLZ site.

However, it is emphasized that the monthly medians may include both quiet and disturbed days in its calculation and so are disregarded in the new DIX calculation (see results from May in Fig. 3). The other methods (TEC-IRI and 6hMAQd) presented high $\chi$-values and therefore were also disregarded methods. Each color represents the $x$-values monthly variation for each nonperturbed reference method during the year 2015 (black: monthly medians, red: TEC-IRI, blue: 1hMAQd, orange: 3hMAQd, and green: 6hMAQd), for the three TEC sites (SLZ, SJC, and SMA).

Table 1 - The annual average of dispersion coefficient values obtained for each non-perturbed reference method at the three TEC sites, for the year 2015.

\begin{tabular}{|c|c|c|c|c|c|}
\hline \multicolumn{5}{|c|}{ Disp. Coeff. $(\chi)$ - Annual Average } \\
\hline Loc. & Median & IRI & 1hMAQd & 3hMAQd & 6hMAQd \\
\hline SLZ & 0.08 & 0.40 & 0.06 & 0.08 & 0.15 \\
\hline SJC & 0.18 & 0.38 & 0.14 & 0.16 & 0.22 \\
\hline SMA & 0.14 & 0.39 & 0.13 & 0.17 & 0.23 \\
\hline
\end{tabular}

Figure 3 shows that the dispersion coefficient of the 1hMAQd method presented low values ranging from 0 to about 0.2 for all TEC sites, attesting to the good performance of the method. The 3hMAQd method presented dispersion 


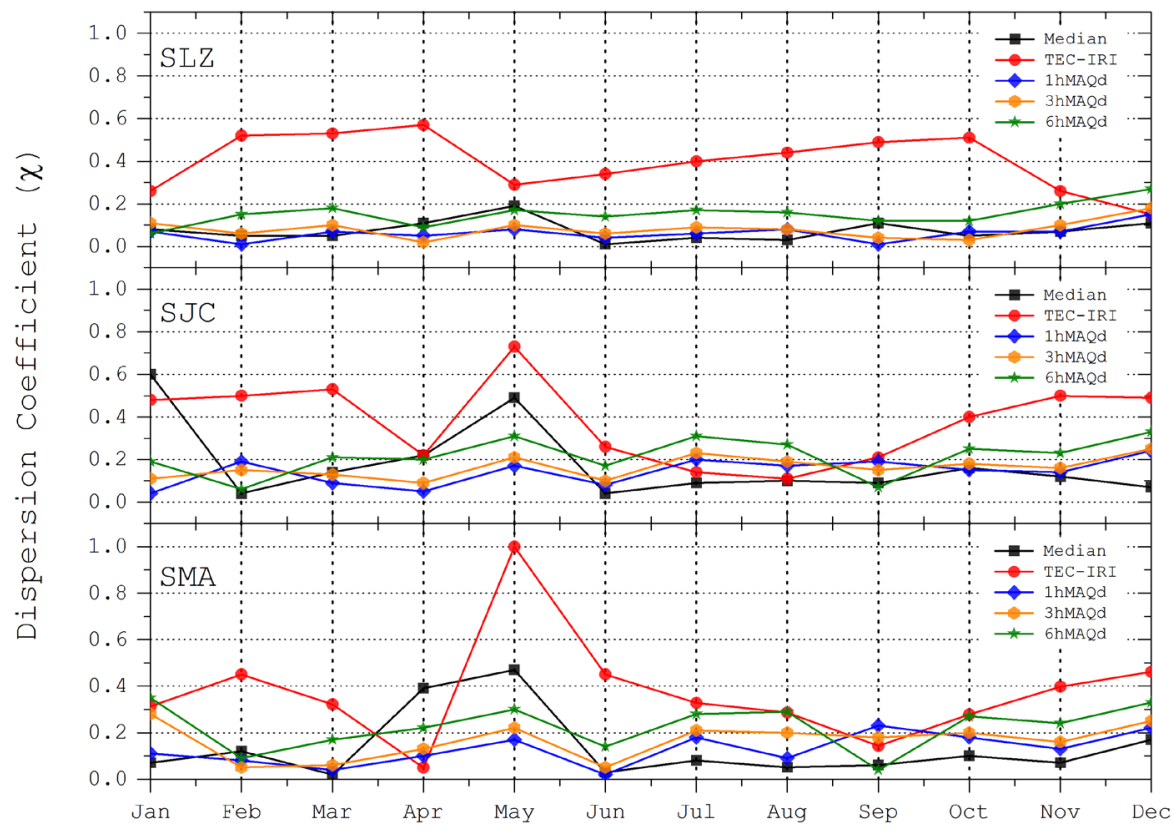

(a)

(b)

(c)

Figure 3 - The annual variation of dispersion coefficient values related to the monthly medians (black squares), TEC-IRI (red circles), 1hMAQd (blue diamonds), 3hMAQd (orange hexagons), and 6hMAQd (green stars) at (a) SLZ, (b) SJC, and (c) SMA during 2015.

values similar to those obtained for the 1hMAQd method, along with the same consistency. The difference between the dispersion coefficients of these methods is 0.03 , which shows that the use of the 3hMAQd method instead of 1hMAQd in the new DIX calculation is not greatly affected. Regarding the monthly medians, the dispersion coefficient presented inconstant values during January, April, and May, which confirms that this method is strongly influenced by outliers. Moreover, the TEC-IRI and 6hMAQd methods were disregarded because their dispersion coefficient values remained very high throughout the entire period.

Thus, the selected method for determining of the new DIX non-perturbed reference was the one represented by a 3hour moving average over the TEC obtained during the reference day. Thereafter, we calculate and validate the new DIX calculated from Equation (2) using the 3hMAQd method during the period around the St. Patrick's Day magnetic storm.

\section{Validation and application in a space weather event}

The aim here is to study the ionospheric response during an extreme magnetic storm, discussing the observed differences when applying the new TEC reference on the Equation (2) and using the original DIX methodology. Thus, we have chosen the St. Patrick's Day magnetic storm (17-18 March 2015) to discuss the observed differences in the DIX values obtained from both methodologies. The temporal variations of interplanetary and geophysical parameters during this storm are detailed in Astafyeva et al. (2015). Figure 4 shows the new DIX time variation (panel 'a') superposed by the Dst index from 16 to 21 March 2015, at the SJC TEC site. Furthermore, 14 March was chosen to be the reference day for the calculation of the 3hMAQd values. The panel 'b' presents the same parameters as on the previous panel, but this time showing the original DIX time variation, where the nonperturbed reference was obtained by the method of the monthly medians. It is important to mention that the original DIX scale ranging from 0 to 2 was chosen to observe the original method's peaks better and compare it with the new approach. At last, the panel 'c' presents the time variation for the non-perturbed curves obtained from the 3hMAQd (red curve) and Median (blue curve) methods, as well as the daily TEC variation (gray curve) related to the studied period. Hatched are identified by the numbers from 1 to 4 to point out time intervals on which this analysis is focused.

Throughout this period of study, the Dst index values remained close to zero on 16 March. However, on 17 March the occurrence of an extreme magnetic storm caused the Dst index value to decrease to about - $223 \mathrm{nT}$ during the magnetic 


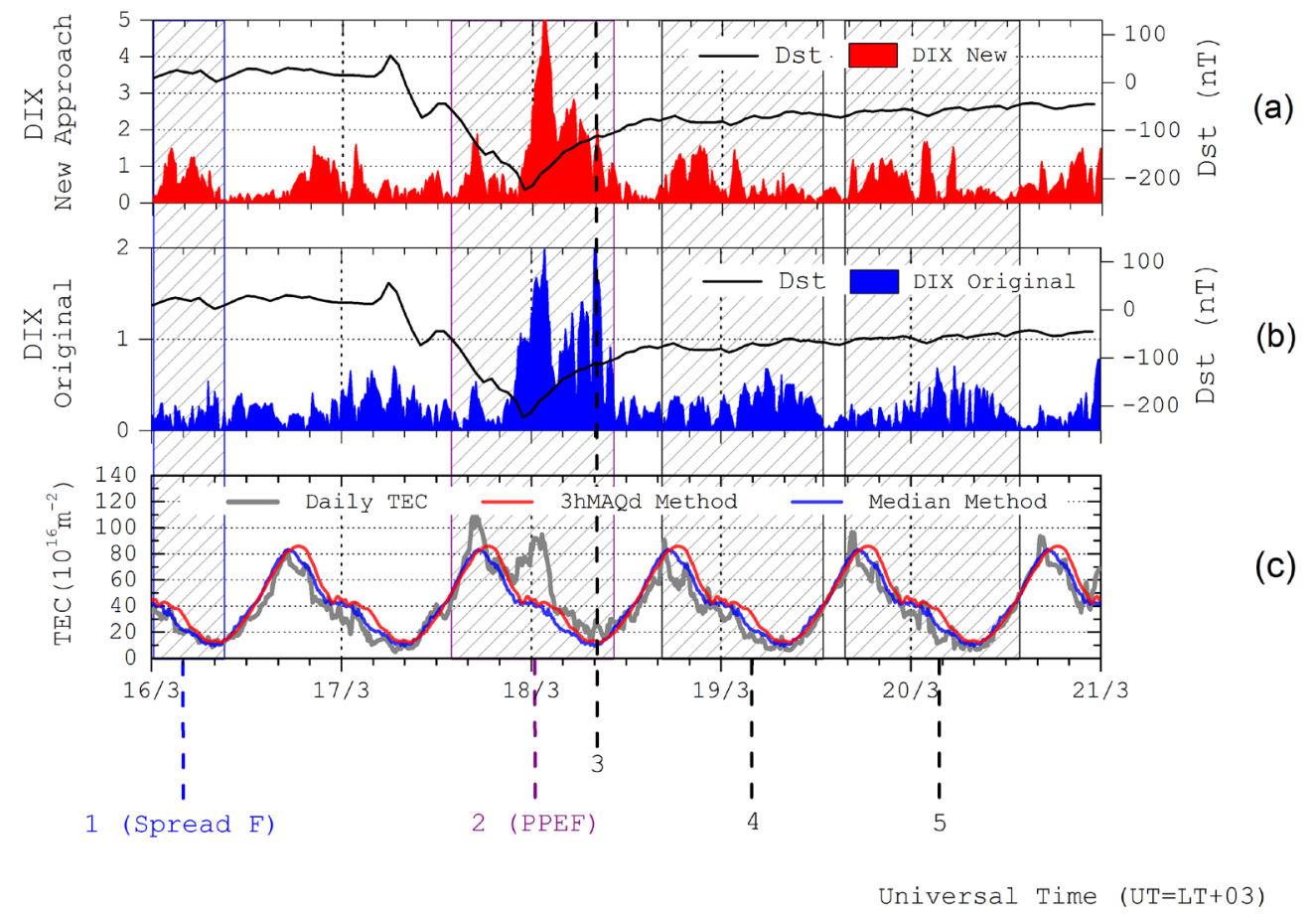

Figure 4 - Time variation of (panel 'a') new DIX and (panel 'b') original DIX, superposed by the Dst index, and nonperturbed references (panel 'c') used for their calculation along with the daily TEC during the period around the St. Patrick's Day magnetic storm.

storm main phase, which lasted until near 00:00 UT on 18 March. It is also noteworthy that this event is known as the St. Patrick's Day magnetic storm and its effects on the ionosphere have continuously been studied (Astafyeva et al., 2015; Venkatesh et al., 2017; Barbosa et al., 2018). Regarding the time evolution of this space weather event, the storm recovered on 25 March, with Dst index values approaching zero around 13:00 UT (Venkatesh et al., 2017; Maurya et al., 2018).

It should be noted that the new DIX detected clearly the occurrence of ionospheric disturbances, while these responses presented some inconsistencies when observed in the original DIX values. For instance, on 16 March around 00:00-09:00 UT we can see that the new DIX presented two periodic peaks ranging between scales 1 and 2 (hatched area 1), which is barely observed by the original DIX.

These disturbances are strongly associated with spread-F in the pre-storm period (see ionograms in Fig. 5). Hence, while the new DIX presented a clear and periodic behavior in detecting the Spread F TEC response, the original DIX presented a noisy behavior, not unlike the one observed throughout the entire daily variation for 16 March.
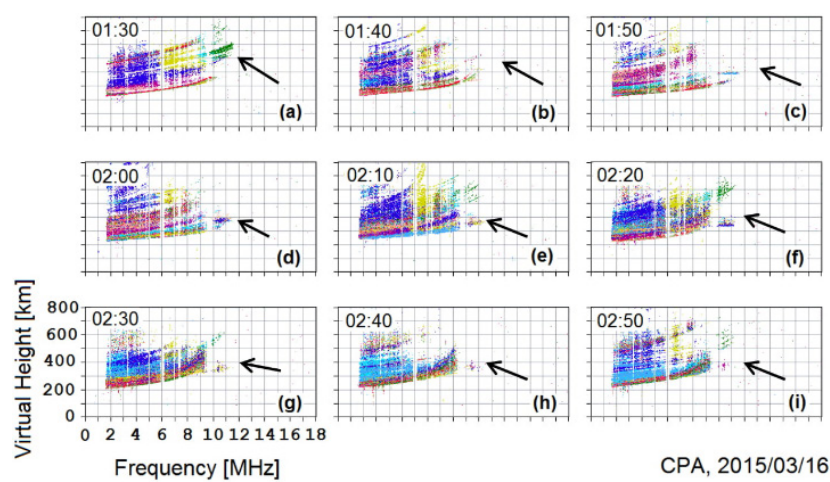

Figure 5 - Sequence of ionograms from 01:30 UT to 02:50 UT on March 16, 2015, demonstrating the presence of spread- $F$ over Cachoeira Paulista (same SJC observation point). Black arrows indicate spread of the signal.

On the 17th, during the storm main phase, it can be observed in both DIX methodologies a slight disturbance between 14:00 UT, which extends to 10:00 UT on the 18th. These peaks are directly associated with TEC increases 
related to the storm-related Prompt Penetration Electric Field (PPEF) occurrence in low latitudes (Venkatesh et al., 2017). Regarding the daytime TEC increases due to PPEF, both indices had a similar response. However, it can be seen that the original DIX tended to overestimate nighttime TEC increases (vertical line ' 3 '), which may be a direct consequence of the original DIX equation, which considers a percentage variation in its calculation. In contrast, the original DIX presented a quite progressive behavior during the PPEF occurrence, gradually increasing its value to the level 5 (extremely disturbed state), and then decreasing until it returned to near zero (quiet state). At the same time, the electric field became less effective in disturbing the TEC.

Other indications of overestimation in the original DIX nighttime ionospheric response can also be seen on the 19th and 20th (hatched areas 4 and 5, respectively), where the difference between the measured daily TEC and the median-based reference is clearly smaller at night, however, the index shows higher values. The same is not seen in the new DIX values, which show a response consistent with the difference between the measured daily TEC and the 3hMAQd reference, irrespective of the day.

\section{CONCLUSIONS}

In this paper, we evaluated the method to determine the non-perturbed TEC reference for the new DIX as it was described in Denardini et al. (2020). The conclusions are summarized below:

Monthly medians can be highly influenced by influenced by outliers since its dispersion coefficient presented inconstant values in January, April, and May. The authors recommend not using such a method.

TEC-IRI method was disregarded because its dispersion coefficient values remained very high throughout the entire period of study.

All non-perturbed TEC references tend to be more dispersed (concerning the qTEC values) on the site near the EIA southern crest (SJC).

The non-perturbed TEC reference method that comes closest to qTEC is the one obtained from the calculation of a 1-hour moving average over the TEC obtained during the reference day (1hMQd). However, the 3hMAQd method is also a good way to improve the new DIX sensitivity to short time scale ionospheric phenomena, as it was stated in Denardini et al. (2020). The difference between the dispersion coefficients of these methods is 0.03 , which shows that the use of the 3hMAQd method instead of ThMAQd in the new DIX calculation is not significantly affected. Also, both methods demonstrated to have stable dispersion coefficients along the whole year of analysis.

The 3hMAQd method applied to the new DIX calculation showed a better response to magnetic storms than the original DIX, which uses monthly medians. In this context, one of the main advantages of this method is that it minimizes noise due to the TEC seasonal variation, improving the DIX sensitivity to the ionospheric disturbances.

\section{ACKNOWLEDGMENTS}

The authors thank the Embrace/INPE Space Weather Program for providing the TEC data, the IBGE for providing the raw TEC data, and the DIDAE/INPE for providing the ionosonde data to Embrace/INPE. G. A. S. Picanço thanks CNPq/MCTIC (Grant 132252/2017-1) and Capes/MEC (Grant 88887.351778/2019-00). C. M. Denardini thanks CNPq/MCTIC (Grant 303643/20170). P. F. Barbosa Neto thanks Capes/MEC (Grant 1622967). L C. A. Resende would like to thank the China-Brazil Joint Laboratory for Space Weather (CBJLSW), National Space Science Center (NSSC), Chinese Academy of Sciences (CAS) for supporting her postdoctoral fellowship. C. S. Carmo thanks CNPq/MCTIC for supporting her Ph.D (Grant 141935/2020-0). S. S. Chen thanks CNPq/MCTIC (Grant 134151/2017-8) and Capes/MEC (Grant 88887.362982/2019-00). J. Moro thanks the ChinaBrazil Joint Laboratory for Space Weather (CBJLSW), NSSC/CAS for supporting his postdoctoral fellowship, and the National Council for Scientific and Technological Development (CNPq) for the grant 429517/2018-01. R. P. Silva thanks CNPq/MCTIC (Grant 300986/2020-3). 


\section{REFERENCES}

ABDU MA. 2005. Equatorial ionosphere-thermosphere system: electrodynamics and irregularities. Advances in Space Research, 35: 771-787.

ABDU MA, DE SOUZA JR, SOBRAL JHA \& BATISTA IS. 2006. Magnetic storm associated disturbance dynamo effects in the low and equatorial latitude ionosphere. Geophysical Monograph Series, 167: 283-304.

ASTAFYEVA E, ZAKHARENKOVA I \& FÖRSTER M. 2015. Ionospheric response to the 2015 St. Patrick's Day storm: a global multi-instrumental overview. Journal of Geophysical Research, 120: 9023-9037.

BARBOSA FRE, FAGUNDES PR, VENKATESH K, FEJER BG, PILLAT VG, DENARDINI CM \& MUELLA MTAH. 2018. Multi-scale ionospheric irregularities occurrence over South America during the St. Patrick's day storm on March 17, 2015. Journal of Atmospheric and SolarTerrestrial Physics, 174: 32-45.

BATISTA IS, DE PAULA ER, ABDU MA, TRIVEDI NB \& GREENSPAN ME. 1991. Ionospheric effects of the March 13, 1989, magnetic storm at low and equatorial latitudes. Journal of Geophysical Research: Space Physics, 96(A8): 13943-13952.

BILITZA D, ALTADILL D, TRUHLIK V, SHUBIN V, GALKIN I, REINISCH B \& HUANG X. 2017. International Reference Ionosphere 2016: From ionospheric climate to real-time weather predictions. Space Weather, 15(2): 418-429.

BLANC M \& RICHMOND AD. 1980. The ionospheric disturbance dynamo. Journal of Geophysical Research, 85: 1669-1686.

DENARDINI CM, PICANÇO GAS, BARBOSA NETO PF, NOGUEIRA PAB, CARMO CS, RESENDE LCA, MORO J, CHEN SS, ROMERO-HERNANDEZ E, SILVA RP \& BILIBIO AV. 2020.Ionospheric scale index map based on TEC data for space weather studies and applications. Space Weather, 18: e2019SW002328.

DE SIQUEIRA PM, DE PAULA ER, MUELLA MTAH, REZENDE LFC, ABDU MA \& GONZALEZ WD. 2011. Storm-time total electron content and its response to penetration electric fields over South America. Annales Geophysicae, 29: 1765-1778.

FIGUEIREDO CAOB, WRASSE CM, TAKAHASHI T, OTSUKA Y, SHIOKAWA K \& BARROS D. 2017. Largescale traveling ionospheric disturbances observed by GPS dTEC maps over North and South America on Saint
Patrick's Day storm in 2015, Journal of Geophysical Research: Space Physics, 122, 4755-4763.

FIGUEIREDO CAOB, TAKAHASHI $H$, WRASSE CM, OTSUKA Y, SHIOKAWA K \& BARROS D. 2018. Mediumscale traveling ionospheric disturbances observed by detrended total electron content maps over Brazil. Journal of Geophysical Research: Space Physics, 123: 22152227.

GULYAEVA TL \& STANISLAWSKA I. 2008. Derivation of a planetary ionospheric storm index. Annales Geophysicae, 26(9): 2645-2648.

JAKOWSKI N \& HOQUE MM. 2019. Estimation of spatial gradients and temporal variations of the total electron content using ground-based GNSS measurements. Space Weather, 17: 339-356.

JAKOWSKI N, STANKOV SM, SCHLUETER S \& KLAEHN D. 2006. On developing a new ionospheric perturbation index for space weather operations. Advances in Space Research, 38: 2596-2600.

JAKOWSKI N, BÉNIGUEL Y, DE FRANCESCHI G, PAJARES MH, JACOBSEN KS, STANISLAWSKA I, TOMASIK L, WARNANT $R$ \& WAUTELET G. 2012a. Monitoring, tracking and forecasting ionospheric perturbations using GNSS techniques. Journal of Space Weather and Space Climate, A22: 1-14.

JAKOWSKI N, BORRIES C \& WILKEN V. 2012b. Introducing a disturbance ionosphere index. Radio Science, 47(4): RSOL14, 1-9.

KELLEY MC, FEJER BG \& GONZALES CA. 1979. An explanation for anomalous ionospheric electric fields associated with a northward turning of the interplanetary magnetic field. Geophysical Research Letters, 6: 301-304.

MAURYA AK, VENKATESH K, KUMAR S, SINGH R, TIWARI P \& SINGH AK. 2018. Effects of St. Patrick's day geomagnetic storm of March 2015 and of June 2015 on low-Equatorial D region ionosphere. Journal of Geophysical Research, 123: 6836-6850.

NOGUEIRA PAB, ABDU MA, BATISTA IS \& DE SIQUEIRA PM. 2011. Equatorial ionization anomaly and thermospheric meridional winds during two major storms over Brazilian low latitudes. Journal of Atmospheric and Solar-Terrestrial Physics, 73: 1535-1543.

RESENDE LCA, DENARDINI CM, PICANÇO GAS, MORO J, BARROS D, FIGUEIREDO CAOB \& SILVA RP. 2019. On developing a new ionospheric plasma index for the 
Brazilian equatorial $F$ region irregularities. Annales Geophysicae, 37: 807-818.

SANZ J, JUAN J,M, GONZÁLEZ-CASADO G, PRIETOCERDEIRA R, SCHLÜTER S \& ORÚS R. 2014. Novel Ionospheric Activity Indicator Specifically Tailored for GNSS Users. In: 27th International Technical Meeting of the Satellite Division of The Institute of Navigation (ION GNSS+ 2014). Proceedings... Tampa, Florida, September 2014, p. 1173-1182.

SHINBORI A, OTSUKA Y, TSUGAWA T, NISHIOKA M, KUMAMOTO A, TSUCHIYA F, MATSUDA S, KASAHARA $Y$, MATSUOKA A, RUOHONIEMI JM, SHEPHERD SG \& NISHITANI N. 2018. Temporal and spatial variations of storm time midlatitude ionospheric trough based on global GNSS-TEC and Arase satellite observations. Geophysical Research Letters, 45: 7362-7370.

SOBRAL JHA, ABDU MA, GONZALEZ WD, TSUTURANI BT, BATISTA IS \& GONZALEZ AL. 1997. Effects of intense storms and substorms on the equatorial ionosphere / thermosphere system in the American sector from groundbased and satellite data. Journal of Geophysical Research: Space Physics, 102(A7): 14305-14313.

TAKAHASHI H, WRASSE CM, DENARDINI CM, PÁDUA MB, DE PAULA ER, COSTA SMA, OTSUKA Y, SHIOKAWA
K, GALERA MONICO JF, IVO A \& SANT'ANNA N. 2016. Ionospheric TEC Weather Map Over South America. Space Weather, 14(11): 937-949.

TAKAHASHI $H$, WRASSE CM, FIGUEIREDO CAOB, BARROS D, ABDU MA, OTSUKA Y \& SHIOKAWA K. 2018. Equatorial plasma bubble seeding by MSTIDs in the ionosphere. Progress in Earth and Planetary Science, 5:32, 1-13.

TSUGAWA T, NISHIOKA M, ISHII M, HOZUMI K, SAITO S, SHINBORI A, OTSUKA Y, SAITO A, BUHARI S, ABDULLAH M \& SUPNITHI P. 2018. Total Electron Content Observations by Dense Regional and Worldwide International Networks of GNSS. Journal of Disaster Research, 13(3): 535-545.

VENKATESH K, TULASI RAM S, FAGUNDES PR, SEEMALA GK \& BATISTA IS. 2017. Electrodynamic disturbances in the Brazilian equatorial and low-latitude ionosphere on St. Patrick's Day storm of 17 March 2015. Journal of Geophysical Research: Space Physics, 122: 4553-4570.

WILKEN V, KRIEGEL M, JAKOWSKI N \& BERDERMANN J. 2018. An ionospheric index suitable for estimating the degree of ionospheric perturbations. Journal of Space Weather and Space Climate, 8(A19): 1-9. 